\title{
Mechanism and Morphology of Formation of Micropores in the Structure of DC Cast AIMgSi Alloy
}

\author{
I. Buljeta ${ }^{1 \mathrm{i}}$, Z. Zovko Brodarac ${ }^{2}$, A. Beroš ${ }^{1, *}$, M. Zeko ${ }^{1}$ \\ ${ }^{1}$ Faculty of Metallurgy and Materials Science, University of Zenica, Zenica, Bosnia and Herzegovina \\ ${ }^{2}$ Faculty of Metallurgy, University of Zagreb, Sisak, Croatia
}

Copyright $(2017$ by authors, all rights reserved. Authors agree that this article remains permanently open access under the terms of the Creative Commons Attribution License 4.0 International License

\begin{abstract}
The phenomena defects in the triple junction grain boundaries affect the properties of the microstructure of aluminum alloys. For that purpose the microstructure of the alloy EN AW 6060 on the billet sample cast by DC (Direct Chill) technology was analysed in order to gain insight into the origin and form pores in the final stages of solidification. Mechanisms of solidification shrinkage, thermal contraction and low permeability of interdendritic channels networks were discussed in moment when melt becomes isolated in separate locations forming new structure. Under such conditions, the tensile stress caused by anisotropic thermal contraction of a coherent dendrites network, causing the formation of pores in the corners of the grain boundaries whose morphology is determined by SEM / EDS analysis.
\end{abstract}

Keywords Micro Cavity-pores-voids, the Triple Point of Grain Boundaries, Hot Tearing, AlMgSi Alloy, Direct Chill Casting

\section{Introduction}

Cracks are formed in the final phase of solidification near a solid temperature. Non-uniform cooling of the Albillet causes hot cracks and describes the stresses when the thin film melt separates the dendrites somewhat. The resulting cracks grow due to stress concentrations, segregation inclusions, Measurement of hardness on the cross section of the billet, the contours of the results that were associated with the strain stresses were obtained. This macro result has been the cause of the search for micro cracks in the critical part of the billet. ${ }^{1}$

The emergence of defects in metal structures includes the nucleation of micropores and microcracks and their further degradation into macroprivatics [1].

Existing theories partially describe cracking factors such as fluid-filled cavities [2, 3], bi-film oxides [4], or microporosity in sagging and thermal contraction at the three-grain boundaries [5]. The cast structure is formed without porosity if the slip-off and thermal contraction is completely compensated by the melt flow through the dendritic network, and later by a high temperature cracking. Conversely, cracks develops require that pores reach critical mass under certain thermomechanical conditions of Griffith's criterion of fracture, so that microporosity and hot cracks can be predicted simultaneously [6]. In addition, pores as potential nuclei of hot cracks may come from captured gas, shrinkage during solidification or excessive saturation of cavities (free spots) [6].

On a micro scale, cavities is characterized by the number of gas atoms in relation to the number of cavities (empty atomic sites in the crystal grid) needed to produce a specific volume of cavity. When the cavity contains only cavities, but not gas atoms, then it is called void [7] which implies that more voids or cavities can form pores. Very often these differences do not stand out, and the macro cavity is open, and the pores are isolated by a closed void.

Solidification Shrinkage in castings has a fundamentally different cause of gas porosity. In the center of the thicker parts of castings there are many small cavities due to shrinkage inside which there is no air or gas, but vacuum. The size of this porosity is often the function of the squeegee speed: large dendrites occur at lower skinning speeds and usually have more irregular and elongated shape. The trapped gas in the balloon is very difficult to separate from the vacuum of the pores.

The formation of microporosity can often be seen on Triple Junctions of Grain Boundaries. The triple compound is a micro defect occurring in a connected grain system where high local stress and density defects (gaps, secondary stages, inclusions, etc.) may be preferable porous or cavity nucleus. These are low-deformation barriers, opening a "privileged" pathway for corrosion, wetting or cavity formation at creep [8]. Triple compounds may have additional energy above the energy of adjacent grain boundaries and for some deformation, the density of dislocation is considerably higher than that of grain boundaries [9] and influence the development of 
microstructure during grain growth [10]. Experimental results show that the motion of the grain boundary system in aluminum can be controlled by three compounds [11].

For the growth mechanism of gaps, the presence of thermal stress is considered to be a dominant factor. The growth of the gaps in aluminum is assumed to diffuse the grain boundary under crushing conditions [12]. Also for a structure in which there is a significant difference in the orientation between grains $\left(>10^{\circ}\right)$, triple compounds are points of high local stress, and lead to a high proportion of cavities [13]. That is why these are nucleation voids, and the high-angle boundaries provide a path for the rapid diffusion of gaps around the grain boundaries to the three-joint [14].

Macroscopic interruption / discontinuity per piece under conditions of hot metal forming, ie, when the deformation temperature is above the half of melting temperature, the main cause of damage development is associated with intergranular damage corresponding to the powder nucleation at the grain boundaries for very low deformation velocities [15]. The deformation velocity, temperature, and strain size are the parameters that determine the origin, shape, size and kinetics of the nucleation and the growth of the micropores. The macroscopic breakdown of the material is compounded by complex mechanisms of action such as a) mobile dislocation, b) nucleation of the cavity, c) continuous cavity growth, d) superplastic growth of the gaps, e) ductile gaps, and f) micro cracks [15].

In hot metal forming and high deformation temperatures, micro cracks occur at the grain boundaries and around the secondary stages, and the cavity shape at the grain boundaries varies with deformation velocity. In these conditions, the following are observed: (1) small gaps at the grain boundaries for high temperatures creep of material $(\varepsilon=10-15 \mathrm{~s}-1)$, then (2) large gaps at the three grain boundary joints at superplastic deformations $(\varepsilon=$ $10-4 \mathrm{~s}-1)$ and (3) wedge cracks at a grain boundary triangle $(\varepsilon=10 \mathrm{~s}-1)$.

There is also an opinion that the cracks are nucleated as a consequence of the grain boundary sliding (as wedge $\mathrm{w}$ type in Figure 1a) or simply generated by spherical gaps accumulation (as a $r$ - type in Figure 1b) [16].

Figure1.

Forming gaps at the grain boundaries is a kinetic phenomenon, and the fracture mode under an arbitrary stress condition depends solely on the rate of nucleation and the rate of growth of the pores. When both speeds are large, there is a possibility for their interconnection to the cavity.

In hot metal shaping, deformation velocities and stresses are high and no gaps in triple grain points are observed. Instead, only microclinical cracks can appear on the grain boundaries. Conversely, in superplastic formatting conditions, with reduced grain size $(<10 \mathrm{~mm})$, the pores are mainly at triple points (Figure 1.c), due to grain rotation and sliding of stressed grain boundaries and deformation velocities significantly higher than the creep rate.
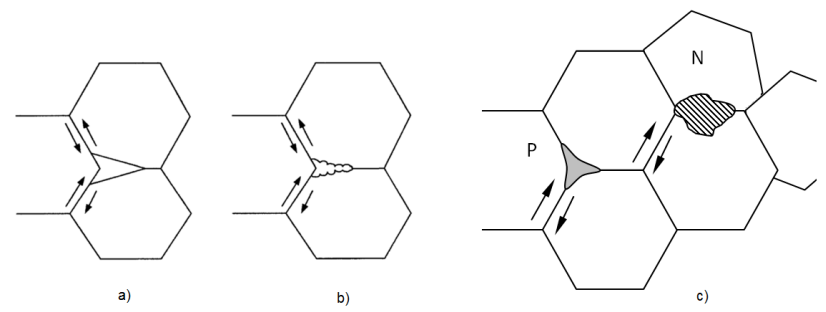

Figure 1. The crack formation pattern a)w and b) the $r$ type [16] and the superplastic formation of the connected pores c) on the tree joints[117]

The further mechanism involves the formation of the rhumb lines on the sloping lines of the drum axis [17]. This procedure is shown in Figure 1.c and it is assumed that during the sliding of the boundaries, the grain group slides as a whole until it is blocked by the unfavorable grain boundaries. This creates the stress concentration on the corresponding triple grain joints and, in the absence of the diffusion, deformation and / or migration of the boundaries, the local concentrated stresses are released by opening the gap at point P. According to the numerical calculations at the sliding limits [18], the opening of such a cavity results in stretched surfaces As a result, further void nucleation takes precedence over these transverse boundaries.

Analysis of the surface of a hot cracking after its emergence can point to different mechanisms and the nature of its formation [18]. Certain types of aluminum alloy castings such as 1000, 3000, 5000 and 6000 have different cracking tendencies depending on the sizing range, grain size, eutectic amount, metal segregation and secondary phases. In hot cracks of the 6000 series alloy such as EN AW 6111, the free dendritic surface may indicate that separation has occurred prior to solidification, i.e. before the dendrite are fully coupled.

Conversely, the aluminum alloy of the 1000 series, such as EN AW 1050, has a narrow suture range (about $10-20^{\circ}$ C) and indicates that hot cracks have sometimes been completely or partially swollen due to the intrusion of molten melt in the interdendritic areas. Alloys from the 5000 series such as EN AW 5182 alloy have little tendency to hot cracks due to the high concentrations of the eutectic phase while the EN AW 3104 alloy shows the surface of the fracture surface at the dendritic tip joint.

\section{Materials and Methods}

Experimental research was carried out at the plant of Aluminum d.d. Mostar on an aluminum hull produced by Direct Chill casting that had thermally induced hot cracks. A sample of EN AW 6060 alloy was tested which, by preliminary microstructure studies, showed the presence of micropores $[19,20]$.

For aluminum alloy series 6000 , hot cracking tests show 
the surface of the fracture that is relatively flat with visible free dendrites without distortion, or pits and hot cracks can be described as a result of interdendritic separation [18]. However, the presence of shrinkage at the solidification can not be excluded from discussion. Therefore, in this paper, it is necessary to further examine this possibility because a wide range of skinning of this alloy will make the last areas that are subjected to subtle stresses due to contraction during a longer temperature interval and thus increase the likelihood of microporosity.

The goal was to investigate the EN AW 6060 alloy with a wide solidification interval $\left(585-650^{\circ} \mathrm{C}\right)$. At this temperature, the mushyzone exists much longer and there is a great tendency to form micropores during the solidification.. In addition, the alloy EN AW 6060 has poor fluidity due to its low content Si and therefore has a very high sensitivity to the emergence of hot cracks.
Primary (As-Cast) alloy EN AW 6060 was cut with inner cracks of $203 \mathrm{~mm}$ diameter and casting lengths of $7500 \mathrm{~mm}$ where the critical casting phase was investigated. SEM / EDS analysis was performed on the log size pattern where the formed structure showed the micropore at the grain boundary triangle.

\section{Results}

The chemical composition of the billet of EN AW 6060 alloy is shown in Table 1 showing the lower content of elements with high melting temperature: $\mathrm{Ti}, \mathrm{Mn}$ and $\mathrm{Cr}$. The reduced content suggests the possibility of forming a larger grain, while $\mathrm{Mn}$ and $\mathrm{Cr}$ are responsible for the kinetics of the secondary AlFeSi phase precipitation during homogenization which, in the case of a defect billet.

Table 1. Chemical composition of EN AW6060 alloy

\begin{tabular}{|c|c|c|c|c|c|c|c|c|c|}
\hline \multirow{2}{*}{ Composition } & \multicolumn{9}{|c|}{ Content of elements ( \%) } \\
\hline & $\mathrm{Si}$ & $\mathrm{Fe}$ & $\mathrm{Cu}$ & $\mathrm{Zn}$ & $\mathrm{Mg}$ & $\mathrm{Mn}$ & $\mathrm{Ti}$ & $\mathrm{Cr}$ & $\mathrm{Na}$ \\
\hline 2 & 3 & 4 & 5 & 6 & 7 & 8 & 9 & 10 & 11 \\
\hline Required & $\begin{array}{l}0,42 \\
0,48\end{array}$ & $\begin{array}{l}0,15 \\
0,25\end{array}$ & $\begin{array}{c}- \\
0,1\end{array}$ & $\begin{array}{c}- \\
0,1\end{array}$ & $\begin{array}{l}0,42 \\
0,48\end{array}$ & $\begin{array}{c}- \\
0,1\end{array}$ & $\begin{array}{c}- \\
0,02\end{array}$ & $\begin{array}{c}- \\
0,05\end{array}$ & 0,007 \\
\hline Achived & 0,4259 & 0,1751 & 0,0013 & 0,0109 & 0,4302 & 0,0413 & 0,0085 & 0,0014 & 0,0016 \\
\hline
\end{tabular}

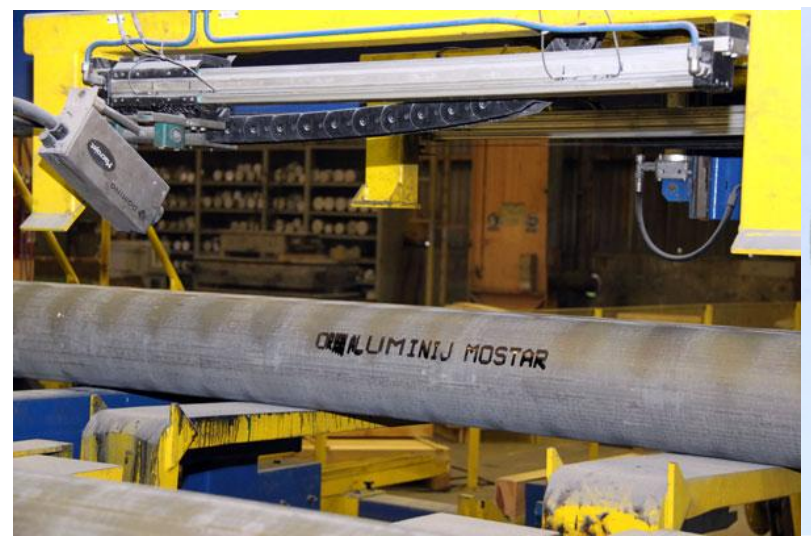

a)

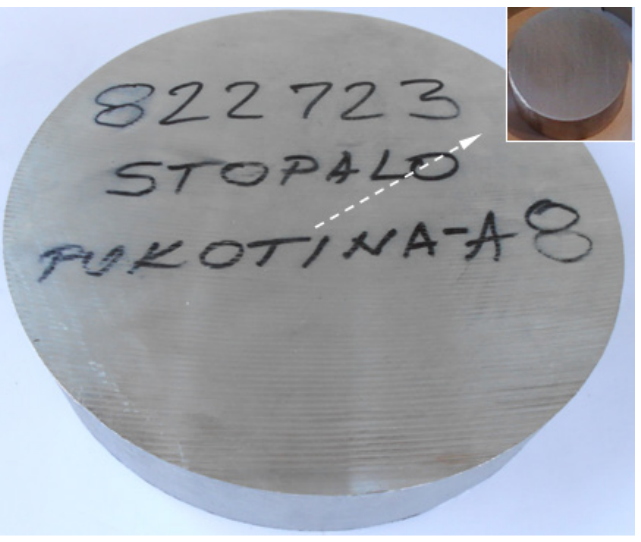

b)

Figure 2. a) Checked billet [21] i b) sample of foot billet and the center section of the billeti EN AW 6060 


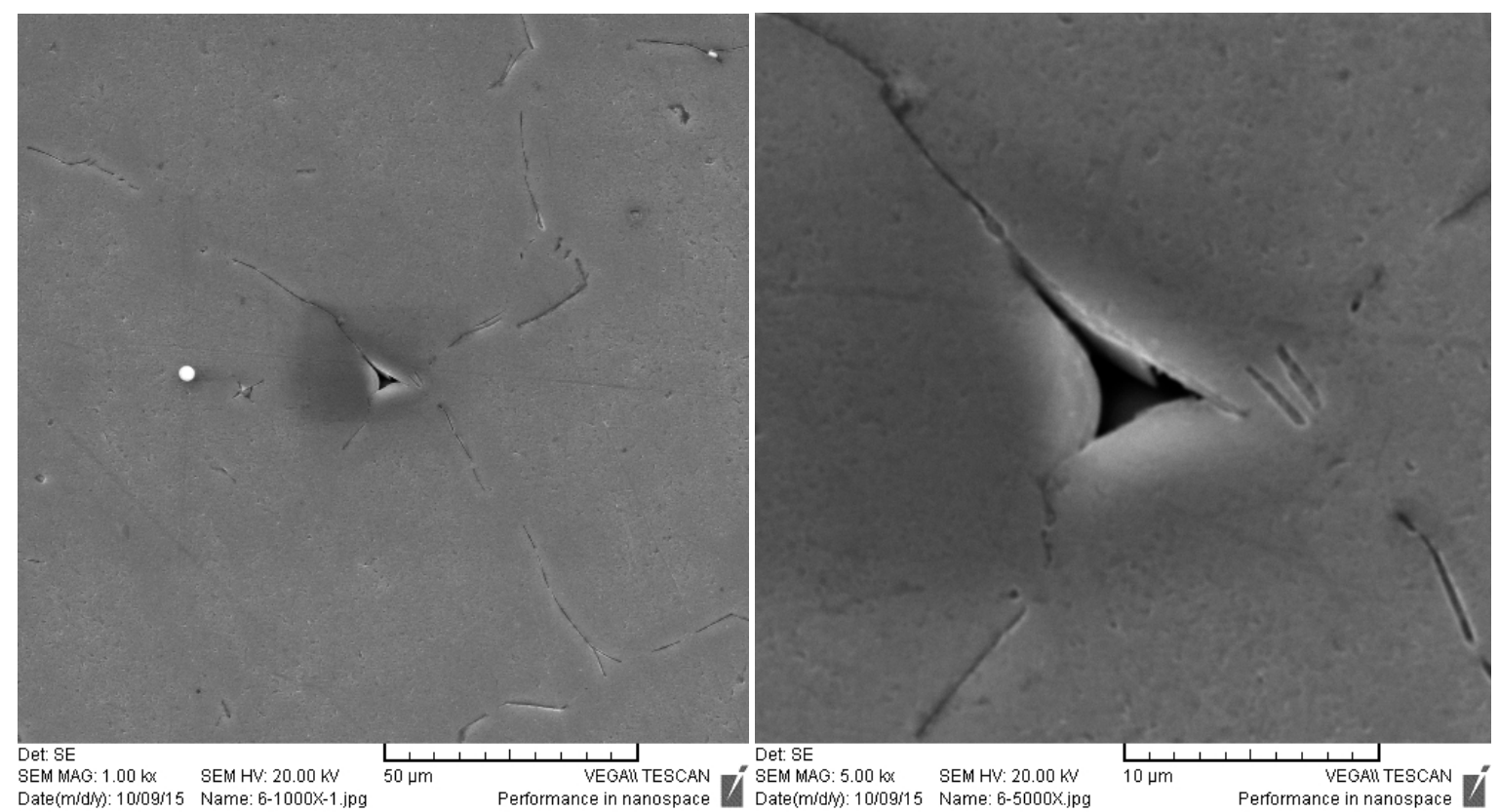

Figure 3. a) Pore on the tree point grains and b) AlFeSi particles of ENAW 6060 alloy

In the next phase, a SEM / EDS test was performed to determine the mechanism of the powder nucleation by determining: (1) the places of origin (2) of the form and (3) the distribution of the key elements in the observed pores.

Although all grain boundaries are not clearly visible, when the sample size is increased by 1000x (Figure 3.a), it is clear that the pores are at the grain boundary point marked A, B and C. In the same Figure 3.a except the open pores at the grain boundaries visible plates of the secondary AlFeSi phase are visible along the grain boundaries.

Large intermetallic particles formed at the early stage of solidification may overcome the $\mathrm{Al}$ dendrite branch and as a result, the semi - solid alloy may improve its strength at lower part of the solid when the cracks are large [6].

In Figure 3.b, at a magnification of 5000x, the possible rest of the broken AlFeSi plate (detail E) and the two AlFeSi particles transversely to the grain boundary (detail F) are visible. In addition to improving stiffness, large intermetallic AlFeSi particles can efficiently block the supply of molten interindividual channels in the mushy zone [6], as indicated by these cross-linked intermetallic particles (detail F, Fig. 3.b).

The shape of the pore in three directions suggests that it was created in a space-wise state, unlike the w-type gaps occurring in the uniaxial tensile test. The top image of the triangular, triangular, $5,5 \mathrm{~mm}$ and $8 \mathrm{~mm}$, refers to its posture, which is the result of: the interplay between shrinkage, thermal contraction and low permeability through the dendritic mesh at the three-point grain boundaries. Therefore, these sites are subject to high local heat stresses during the rapid cooling of billet crust, preferred voids locations

Pores analysis does not point to bullet gas porosity typical of gas porosity but on irregular and elongated shrinkage porosity. The surface area of the pore can refer to the concept of wet granulation of the grain (in case of complete wetting of the grain boundary, the angle $2 \theta$ is equal to zero) [22], but the absence of plastic deformation is more likely to indicate the presence of the porousity due to the solidification.. Along with the fact that the EN AW6060 alloy has a lage range of solidification and a weak fluidity, this prolonged existence of the mushy zone will support the formation of micropores.

In order to identify the content of key elements of $\mathrm{Al}, \mathrm{Si}$, $\mathrm{Fe}, \mathrm{Mg}$ that indicate to pores or a secondary phase $(\mathrm{Mg} 2 \mathrm{Si}$ or $\mathrm{AlFeSi}$ ) as well as inclusion in this site, EDS Elemation Mapping Techniques were performed in the same place where 2D images are displayed spatial arrangement of elements in the sample. Figure 4a shows the dissolved $\mathrm{Si}$, $\mathrm{Fe}$ and $\mathrm{Mg}$ in the aluminum matrix while identifying at the upper edge of the pores is difficult to tell whether it shows the actual elemental compositions of the AlFeSi phase (detail E of Figure 3.b) or the influence of the composition of the matrix surrounding it.

Generally, Figure 4.a shows an increased concentration of $\mathrm{Si}$ in the same place while Figure 4.b clearly shows the absence of aluminum at the pore site, i.e. empty space. 


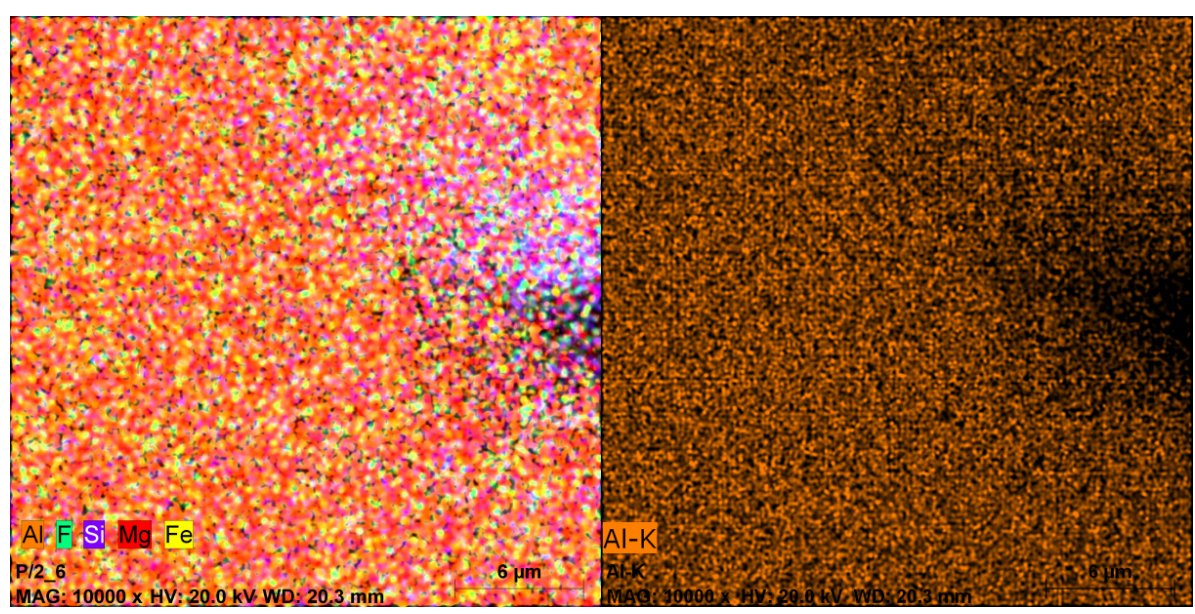

a

b

Figure 4. a). Mapping the key elements and b) the aluminium itself on the sample

Further, for the purpose of a more accurate confirmation of the presence of pore, comparative EDX pore analysis (Figure 5) and adjacent grains were performed (Figure 6).

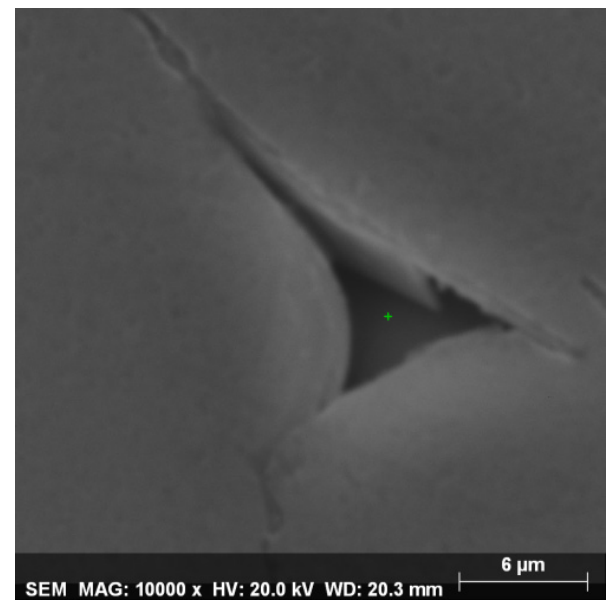

a

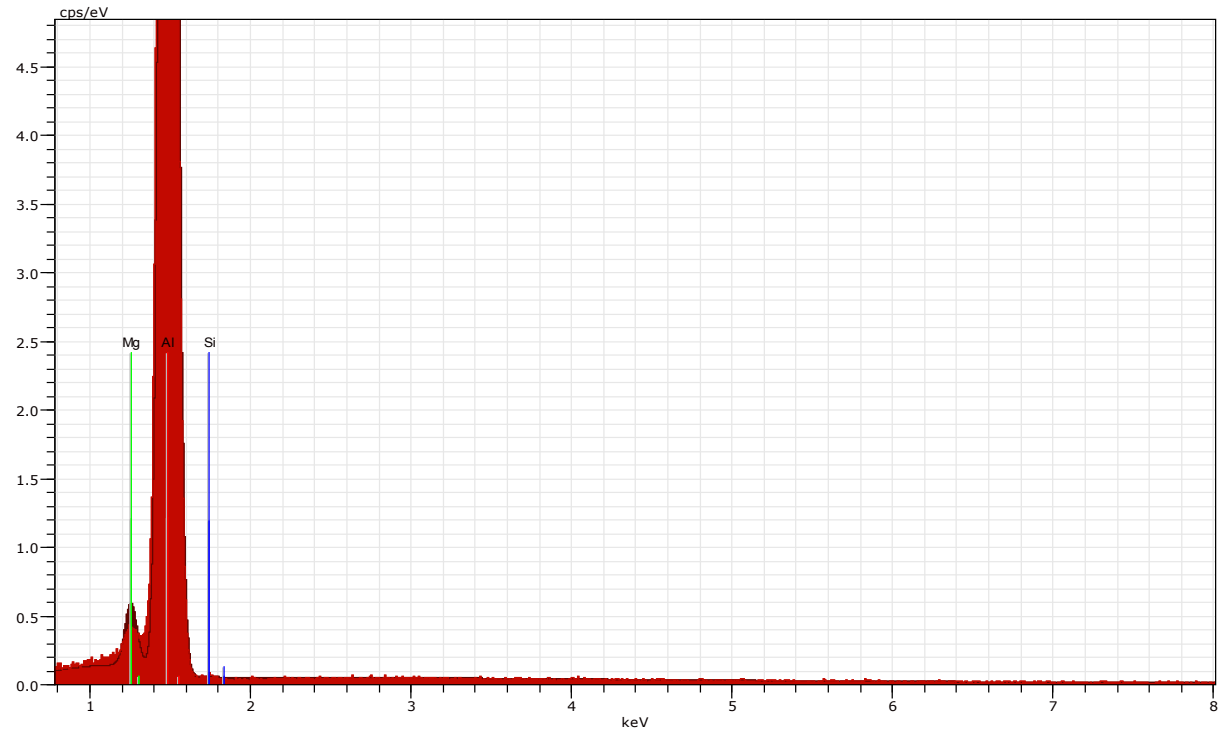

b

Figure. 5a).Measuring site and b)EDX quantitative pore spectrum 

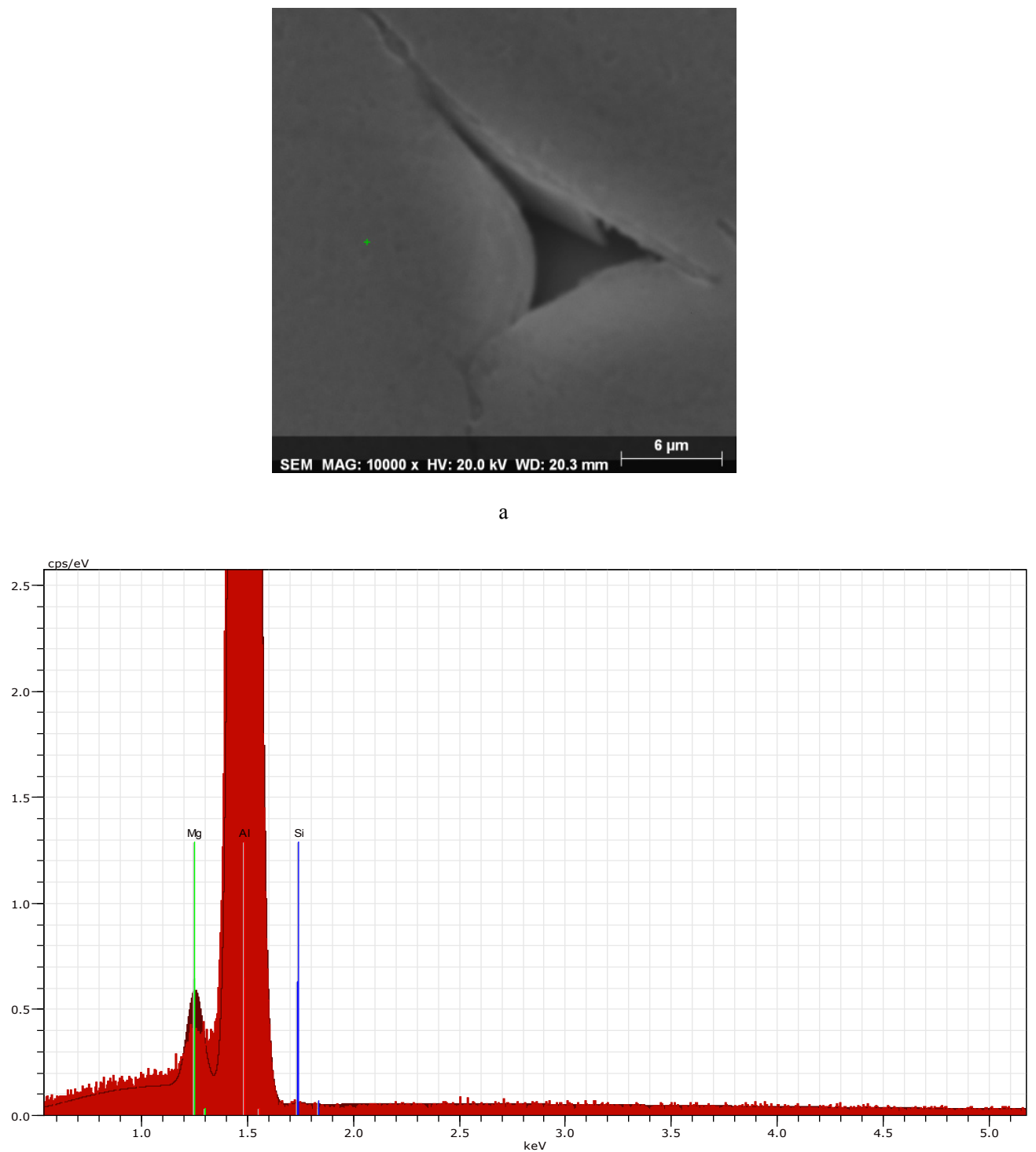

Figure 6. Measuring site and b)EDX quantitative pore spectrum of aluminum alloy grain

The resulting images do not show a clearer picture of the content of $\mathrm{Al}, \mathrm{Mg}$, and $\mathrm{Si}$ on both sites. However, almost identical results within the pores and on the aluminum base show that the lower pore was not opened in depth, ie it did not propagate further into the crack.

As Figures 5 and 6 show no clear distinct difference in the content of the chemical elements, an EDS analysis has been carried out on the cross-section for the same location as shown in Figure $7 \mathrm{a}$. 


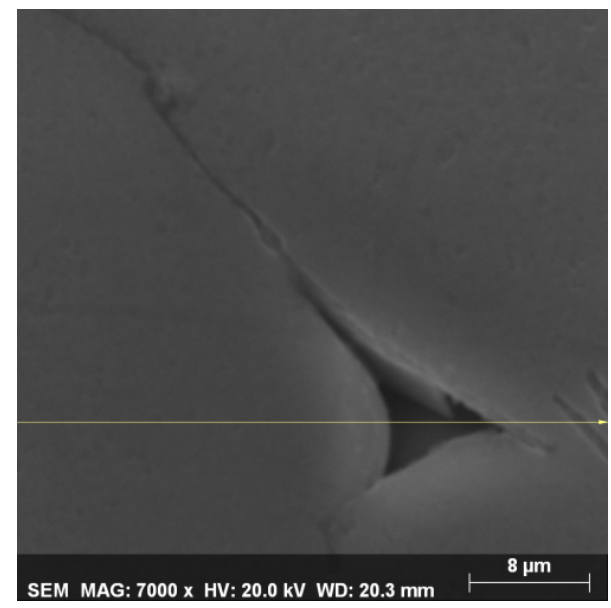

a

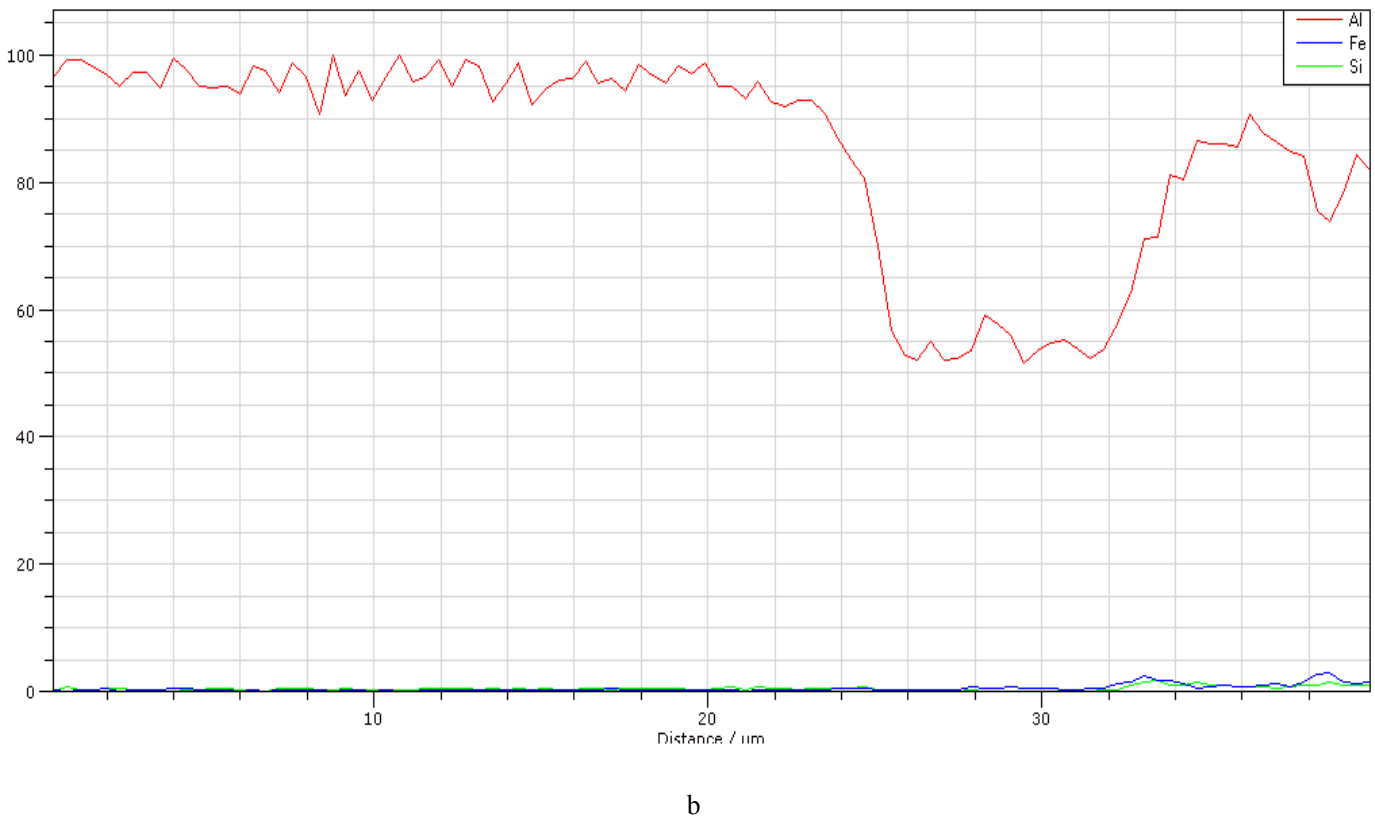

Figure 7. a) Pore and b)The EDS Curve of $\mathrm{Al}$ and $\mathrm{Si}$ on the grain section

The EDS sample pattern diagram clearly demonstrates a drop in the intensity of aluminum content at the beginning and end of the transverse line (pore), indicating an empty space, ie spatial defect at the three-point grain boundary (Figure 7.b). Also, a slight change in the intensity of the curve for $\mathrm{Fe}$ and $\mathrm{Si}$ at the very edge of the pore shows that it is actually the remainder of the AlFeSi particle (Figure 3.b Detail E) which mapping of the elements could not show in Figure 4a. The cross section also transversal (Figure 3.b, detail F) of the AlFeSi part at the end of Figure 7.a right, and the increase in the $\mathrm{Fe}$ and $\mathrm{Si}$ content recorded on the diagram confirms that it is actually the AlFeSi plates that could participate in blocking the flow of liquid between dendrites.

\section{Discussion}

For the alloy of 6060, this type of alloy consists of a free dendritic surface indicating their separation before the end of the solidification or may point to the micropores resulting from the shrinkage [18]. 


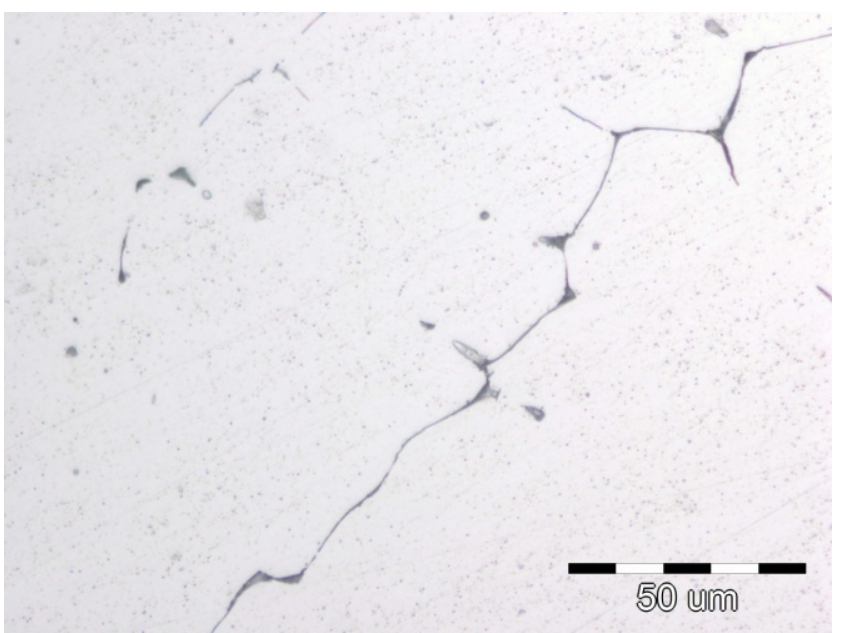

a

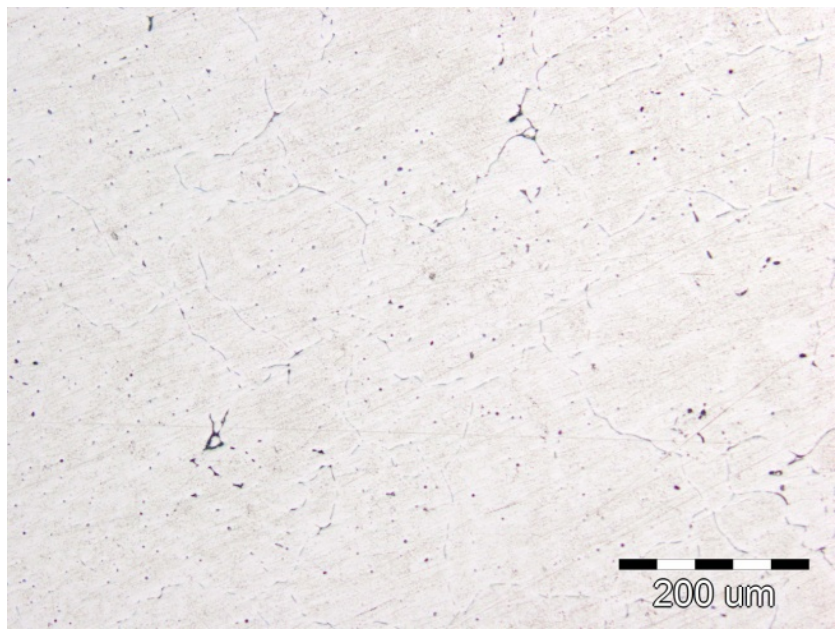

b

Figure 8. a)Microstructure due tobonds and b)Sngle pores on the same sample of the central part of thr crecked billet of the ENAW 6060alloy[23].

Demonstration of metal deformation at high temperatures shows that the shape and size of the pore at the grain boundaries varies from the deformation rate, but is more suited to the deformation direction on the three bonds..

The theory of superplastic materials such as aluminum, for grain size less than $10 \mu \mathrm{m}$, clarifies the formation of microprocesses associated with batches [17] during SPF (Super plastically forming) processing. However, earlier investigations of cracked logs in the Aluminum d.d. foundry Mostar showed only a partial agreement with the aforementioned theory. In the case of aluminum alloy EN AW 6060 and grain size $80-120 \mathrm{~mm}$ due to the rate of deformation velocity during rapid cooling with water, the formation of microprocesses with related portions (Detail A from Figure 8a), as well as the microstructure whose growth was stopped (Detail B i C of Figure 8.a) [23].

The possible mechanism of micropores growth in the hot state of billet, as follows:
1. The EN AW6060 alloy cracking test results indicate that the nucleation of the pores on the three-jointed grain boundaries is due to the curing due to the cracking.

2. EDX depth and adjacent grain analysis identifies individual distal pores that can not be the nucleus of hot cracks, which confirms the details of $\mathrm{B}$ and $\mathrm{C}$ from Figure 8.b [23].

3. The shape of the micropores on SEMs is associated with nucleation which is not the result of sliding adjacent grain boundaries, which best suits the state of spatial stress in the billet during cooling.

4. The superplasticity mechanism is partially non-applicable to alloys which are shrinkaged during solidification formes pores, because the open pores become a stress relaxation site and thus compensate for the transmission of strain deformations along adjacent, similarly oriented grain boundaries.

Because of the imposed thermal stresses, there are two possible microcracks propagation mechanisms between two consecutive pores of the three compounds: (1) the possibility of separating the grain boundaries on the branched AlFeSi particles or (2) the grain boundary sliding by the plastic deformation mechanism. However, such a supposed mechanism of further interconnection of consecutive adjacent pores on the three grain joints and further growth of microcracks should be further explored.

\section{Conclusions}

The microstructure growth mechanism created in the hot state of the billet depends on the type of aluminum alloy. For the EN AW 6060 type alloy, when the alloy passes from liquid to solid phase, a large solidification range extends the period of maintaining the mushy zone, while the conditions of difficult feeding and poor fluidity of the interdendritic channels enable the nucleation of the pores on the three grain bound joints. The mechanism of a coalescence of such pores in the microcracke is still unclear, and points to the pores in the immediate vicinity of two or more similarly oriented grains.

\section{Acknowledgements}

We are greatful for the companies engineering of "Aluminij"d.o.o. - Mostar and "ALLOY WHEELS"d.o.o. Jajce for suggestion and research creative tmosphere.

\section{REFERENCES}

[1] D. Krajcinovic, Damage Mechanics, Amsterdam, 1996 
[2] M. Rappaz, J.-M. Drezet, and M. Gremaud: Metall. Mater. Trans. A, 1999.

[3] Suyitno, W.H. Kool, L. Katgerman: Mater. Sci. Forum, 2002, vols. 396-402, pp. 179

[4] J. Campbell: Castings, Butterworth-Heinemann, United Kingdom, 2003.

[5] W. Suyitno, H. Kool, L. Katgerman. Mater. Sci. Forum, 2002, vols. 396-402, pp. 179-184.

[6] D. Eskin, Physical Metallurgy of Direct Chill Casting of Aluminum Alloys, New Work, 2008.

[7] Glossary of Terms, http://www.paceind.com/die-casting-10 $1 /$ glossary-of-terms

[8] L. Priester, Grain Boundaries, Springer, 2013.

[9] S. Shekhar, A. H. King, Strain fields and energies of grain boundary triple junctions, Acta Materialia, 56 (2008) 19.

[10] G. Gottstein,a L.S. Shvindlermana,b and B. Zhaoa Thermodynamics and kinetics of grain boundary triple junctions in metals, Recent developments 2010.

[11] S. G. Protasova, Triple junction motion in aluminum tricrystals, Acta mater, 49, 2001.

[12] J. Ho , Thermal stress induced voids in nanoscale cu interconnects by in-situ tem heating, Dissertation, The University of Texas, Austin, 2007.

[13] J. Nucci, et all, Local Crystallographic Texture and Voiding in Passivated Copper Interconnects, Applied Physics Letter, 4017-4019, 1996.

[14] R. Keller, J. Nucci, D. Field, Local Textures and Grain Boundaries in Voided Copper Interconnects, Journal of
Electronic Materials, 26, 996-1001,1997.

[15] J. Lin, Y. Liu, T. A. Dean, A Review on Damage Mechanisms, Models and Calibration Methods under Various Deformation Conditions International Journal of DAMAGE MECHANICS, Vol. 14-October, 2005.

[16] M. E. Kassner, M.-T. Perez-Prado, Fundamentals of Creep in Metals and Alloys Elsevier, Technology \& Engineering, 2004, pp.1-279.

[17] A. Farghalli, A. Mohamed, Micrograin Superplasticity: Characteristics and Utilization, Materials, ISSN 1996-1944, 2011.

[18] S. Lin, A study of hot tearing in wrought aluminum alloys, Dissertation, Université du Québec à Chicoutimi (UQAC), 1999.

[19] A. Beroš, I. Buljeta, The influence of induced thermal stresses on the measured hardness in EN AW 6060 alloy billet produced using direct chill casting procedure, Metallurgical \& Materials Engineering Congress of South-East Europe, 2015.

[20] I.Buljeta, A. Beros, Z.Z.Brodarac, The Study Conditions Occurrence of Hot Tearing in the Billets Alloy EN AW6060 Produced with the Process of Direct Chill Casting, Light Metals 2016, Chapt.113, 2016

[21] Proizvodnja, trupci, http://www.aluminij.ba/en/billets

[22] J. Campbell, Castings, ISBN 0750647906 ,Elsevier Science, 2003.

[23] I. Buljeta, A. Beroš, Analysis of the Influence of Composition ENAA-6060(AlMgSi0,5) Aluminum Alloy on the Occurrence of Hot Cracks in the Billets, $10^{\text {st }}$ International Foundrymen Conference, Opatija 2010.

${ }^{\text {i }}$ I. Buljeta, A. Beroš, J. Pristavec \& B. Veber ,MODEL HARDNESS FIELDS as PROJECTIONS THERMALLY INDUCED STRESSES in the EN AW 6060 BILLET MADE by the DIRECT CHILL, MAGMA days, Postdam 2014. 